\title{
DIFERENÇAS ENTRE O MANDADO DE SEGURANÇA INDIVIDUAL E O MANDADO DE SEGURANÇA COLETIVO ${ }^{1}$
}

\author{
Evandro Takeshi Kato \\ Aluno do Curso de Graduação da Faculdade de Direito da USP
}

Resumo:

O presente trabalho tem por objeto a identificação e a análise das diferenças entre o mandado de segurança coletivo introduzido pela Constituição Federal de 1988 e o já consagrado mandado de segurança individual.

Primeiramente, foi realizado um levantamento histórico sobre a utilização do mandado de segurança na defesa de interesses coletivos antes da Constituição Federal de 1988. A seguir foram examinados problemas relativos aos pressupostos, objeto, legitimação é coisa julgada no mandado de segurança coletivo. respeito do tema.

O trabalho se encerra com um capítulo de conclusões finais a

\begin{abstract}
:
The object of the present work is the identification and the analysis of the differences between the mandado de segurança coletivo introduced by the Brazilian Constitution of 1988 and the traditional mandado de segurança individual.

First, it reports the historical development of the use of the mandado de segurança in order to protect collective interests before the Brazilian Constitution of 1988. Following, problems related to the requirements, object, standing to sue and res judicata of the mandado de segurança coletivo are examined.

work.

Conclusive remarks are presented in the last section of this
\end{abstract}

1. A Comissão Julgadora do Prêmio Departamento de Direito Processual, da Faculdade de Direito da Universidade de São Paulo, composta pelos professores Antonio Carlos de Araújo Cintra, José lgnácio Botelho de Mesquita e José Roberto dos Santos Bedaque, em reunizo realizada a 22 de março de 1994, resolveu atribuir o Prêmio de 1993 ao estudante Evandro Takeshi Kato pelo presente trabalho. 
SUMÁRIO:

I - INTRODUÇÃO

II MANDADO DE SEGURANÇA COLETTVO

Histórico; Conceito; Pressupostos; Objeto; Legitimação; Coisa Julgada

III - CONCLUSÃO

IV - BIBLIOGRAFIA

\section{I - INTRODUÇÃO}

A Constituição Federal de 1988 trouxe uma série de inovações no que se refere aos direitos e garantias fundamentais, não mais se limitando aos interesses individuais, estendendo-os aos interesses coletivos e difusos.

A par disso, a atual Constituição introduziu novos institutos para a instrumentalização e garantia desses direitos, tais como o habeas data, mandado de injunção e mandado de segurança coletivo.

$O$ presente trabalho tem por objeto a identificação e a análise das diferenças entre o mandado de segurança coletivo e o já consagrado mandado de segurança individual.

Trata-se de tarefa dificil e complexa tanto pela inexistência de legislação infraconstitucional, regulamentando especificamente $o$ mandado de segurança coletivo, como também pela polêmica que envolve o tema.

Tomando como ponto de partida o próprio texto constitucional e subsidiariamente a legislação ordinária referente ao mandado de segurança individual, procedeu-se a um amplo levantamento doutrinário e jurisprudencial acerca do mandado de segurança coletivo.

\section{MANDADO DE SEGURANÇA COLETIVO}

\section{Histórico:}

O mandado de segurança individual foi criado pela Constituição Federal de 1934. De lá para cá, o mandado de segurança foi previsto em todas as constituições brasileiras, com exceção da Constituição de 1937. Durante a vigência desta, o mandado de segurança persistiu como mero instrumento legal, com previsão na Lei n. 191, de 16 de janeiro de 1936. 
Antes mesmo da atual Constituição, já se cogitava da possibilidade da utilização do mandado de segurança para a defesa de interesses coletivos.

O principal obstáculo a ser vencido consistia na regra geral disposta no art. $6^{\circ}$ do Código de Processo Civil, consoante a qual "ninguém poderá pleitear em nome próprio, direito alheio, salvo quando autorizado por lei."

Em determinados casos, no entanto, a legislação vigente autorizava a defesa judicial de interesses coletivos.

$\mathrm{O}$ art. 513, a, da Consolidação das Leis do Trabalho outorgava aos sindicatos a prerrogativa de "representar, perante as autoridades administrativas e judiciárias, os interesses gerais da respectiva categoria ou os interesses individuais dos associados relativos à atividade ou profissão exercida."

O Estatuto da Ordem dos Advogados do Brasil também dispõe de semelhante prerrogativa: "Cabe à Ordem representar, em juizo e fora dele, os interesses gerais da classe dos advogados $e$ os individuais, relacionados com o exercício da profissão." (art. $1^{\circ}$. parágrafo único da Lei n. 4.215/63).

Assim, tomando-se por base esses dois dispositivos legais, foram impetrados mandados de segurança por sindicatos e pela $\mathrm{OAB}$ para a defesa de interesses de seus membros, sendo, em alguns casos, reconhecida a legitimidade processual dessas entidades.

Cabe ressaltar, porém, que o entendimento jurisprudencial predominante negava a utilização de mandado de segurança pelos sindicatos na defesa de seus membros.

Com a promulgação da Constituição de 1988, consolidou-se o direito dessas entidades, ao lado dos partidos políticos e associações e entidades de classe, de impetrar o mandado de segurança coletivo.

\section{Conceito:}

O mandado de segurança individual e o coletivo estão previstos pela Constituição Federal de 1988, em seu art. $5^{\circ}$ incisos LXIX e LXX, respectivamente: 
"Art. $5^{\circ}(\ldots)$

LXIX - conceder-se-á mandado de segurança para proteger direito líquido e certo, não amparado por habeas corpus ou habeas data, quando o responsável pela ilegalidade ou abuso de poder for autoridade pública ou agente de pessoa jurídica no exercicio de atribuições do Poder Público.

LXX - o mandado de segurança coletivo pode ser impetrado por:

a) partido politico com representação no Congresso Nacional;

b) organização sindical, entidade de classe ou associação legalmente constituída e em funcionamento há pelo menos um ano, em defesa dos interesses de seus membros e associados."

À primeira vista, a disposição do texto constitucional nos leva a crer que se trata de dois remédios constitucionais distintos e autônomos. $\mathrm{O}$ mandado de segurança coletivo está previsto pela Constituição em um inciso próprio.

No entanto, o mandado de segurança coletivo deve ser entendido como espécie do mandado de segurança tradicional, conforme procuraremos demonstrar nos ítens seguintes deste trabalho.

Assim, podemos conceituar o mandado de segurança coletivo como sendo o remédio constitucional que visa à proteção de direito líquido e certo, não amparado por habeas corpus e habeas data, quando o responsável pela ilegalidade ou abuso de poder for autoridade pública ou agente de pessoa jurídica no exercício das atribuições do Poder Público, a ser utilizado por partidos políticos com representação no Congresso Nacional, organizações sindicais, entidades de classe ou associações legalmente constituídas e em funcionamento há mais de um ano, em defesa do interesse de seus membros.

A nota característica principal do mandado de segurança coletivo e que vem permitir sua distinção do mandado de segurança individual refere-se à sua legitimação ativa ad causam, que acaba gerando diferenças reflexas quanto ao seu objeto e coisa julgada. 
As duas modalidades de mandado de segurança são, antes de mais nada, verdadeiras ações e por isso devem ser estudadas no âmbito do direito processual.

Quanto à sua natureza, Ada Pellegrini Grinover ${ }^{2}$ define o mandado de segurança coletivo e individual como sendo "ações que a Constituição atribuiu na feliz expressão de Kazuo Watanabe - eficácia potenciada."

E ressalva a eminente professora: ${ }^{3}$ "Do fato de ser o mandado de segurança ação de eficácia potenciada, surge mais uma conseqüencia, que se reflete no principio da efetividade do processo, reforçando-o."

\section{Pressupostos:}

A primeira indagação que se impõe, diz respeito aos pressupostos genéricos do mandado de segurança individual, exigidos pela Constituição, ou seja:

a) direito líquido e certo, $\mathrm{e}$

b) ato ilegal ou abusivo de autoridade, não amparado por habeas corpus ou habeas data.

Esses pressupostos genéricos devem também estar presentes no mandado de segurança coletivo?

A resposta nos parece ser afirmativa. Esta é, aliás, a posição majoritária na doutrina e também na jurisprudência.

a) direito líquido e certo

Segundo Lúcia Valle Figueiredo, "parece-nos que, inobstante não tenha o inciso $L X X$, do prefalado artigo $5^{\circ}$, tornado a se referir a direito líquido $e$ certo, é incontroversa sua necessidade."

No magistério do saudoso Hely Lopes Meirelles:" "quando a lei alude a direito líquido e certo, está exigindo que esse direito se apresente com todos os requisitos para o seu reconhecimento e exercício no momento da impetração. Em

2. "Mandado de Segurança Coletivo: Legitimação, Objeto e Coisa Julgada". In Revista de Processo, São Paulo, v. 15, n. 58, p. 75 e 76, abr./jun. 1990.

3. Ibid., p.76.

4. Perfil do Mandado de Segurança Coletivo, São Paulo, Revista dos Tribunais, 1989, p. 11.

5. Mandado de Segurança, Ação Popular, Ação Civil Pública, Mandado de Injunção, Habeas Data, 13` ed., São Paulo, Revista dos Tribunais, 1989, p. 14. 
última análise, direito líquido e certo é direito comprovado de plano. Se depender de comprovação posterior não é líquido nem certo, para fins de segurança."

Cabe aqui a observação feita por Lúcia Valle Figueiredo: 6 "o direito deve ser certo quanto aos fatos, muito embora possa - e efetivamente haja controvérsia de direito."

A necessidade de direito líquido e certo para a impetração de mandado de segurança coletivo justifica-se pela celeridade que deve caracterizar o writ. A dilação probatória é igualmente incompatível com o mandado de segurança coletivo. $^{?}$

Sobre a questão da necessidade de prova pré-constituída, já se manifestou o Pretório Excelso, no Mandado de Segurança Coletivo n. 21098-DF, tendo como relator o Ministro Sepúlveda Pertence:

\begin{abstract}
"MANDADO DE SEGURANÇA COLETIVO PETIÇÃO INICIAL DESACOMPANHADA DE DOCUMENTO ESSENCIAL FALTA DE COMPROVAÇÃO DE QUE A IMPETRANTE É ENTIDADE LEGALMENTE CONSTITUIDA E EM FUNCIONAMENTO HÁ PELO MENOS UM ANO - IMPOSSIBILIDADE DE DILAÇÃO PROBATÓRIA - MANDADO DE SEGURANÇA NÃO CONHECIDO.

- A ação de mandado de segurança ainda que se trate do writ coletivo, que se submete às mesmas exigências $e$ aos mesmos princípios básicos inerentes ao mandamus individual - não admite, em função de sua própria natureza, qualquer dilação probatória. $\dot{E}$ da essência do processo de mandado de segurança a caracteristica de somente admitir prova literal pré-constituida, ressalvadas as situações excepcionais previstas em lei (Lei. n. 1533/51, art. 6o e seu parágrafo único)." (DJU, de 27.03 .92$, p.3802)
\end{abstract}

\footnotetext{
6. Ob. cit., p. 10
}

7. Nesse sentido: STJ - MS n. 1255-DF, DJU de 29.06.92, p.10247; MS n. 845-DF DJU de 16.03.92, p.3070; TRF 2^ Região (RJ) - MS n' 213921, DJU de 28.12.90. 
b) ato de autoridade

Para Hely Lopes Meirelles: ${ }^{8}$ "ato de autoridade é toda manifestação ou omissão do Poder Público ou de seus delegados, no desempenho de suas funções ou a pretexto de exercê-las."

O mandado de segurança coletivo necessita igualmente da ocorrência de ato ilegal ou abusivo de autoridade para a sua impetração.

No que se refere a ato de autoridade para efeitos de mandado de segurança coletivo entendemos estarem excluídos a lei em tese e atos normativos abstratos, sendo aplicável a Súmula 266 do STF, que apresenta o seguinte enunciado: ${ }^{9}$

\footnotetext{
"266 - Não cabe mandado de segurança contra lei

em tese."
}

\section{Objeto:}

O objeto do mandado de segurança é a anulação ou retificação do ato ou omissão da autoridade, que fira ou ameace direito líquido e certo. Essa definição genérica serve para ambos os tipos de mandados de segurança. A distinção entre os dois se dá no âmbito dos direitos líquidos e certos tutelados por cada um deles.

No que tange ao mandado de segurança individual, este se destina à proteção de direito individual, vinculado à própria pessoa do impetrante.

A questão se complica, no entanto, quando se procura determinar a extensão dos direitos tutelados pelo mandado de segurança coletivo.

Antes de mais nada, mister se faz estabelecer distinções entre interesses coletivos e interesses difusos.

Segundo Ada Pellegrini Grinover: ${ }^{10}$ "A diferença consiste em que se entende por interesses difusos aqueles em que não há nenhum vinculo jurídico entre as pessoas pertencentes ao grupo, ligadas que são apenas por circunstâncias de fato, contingentes e variáveis, como as de habitarem a mesma região ou o

8. Ob. cit., p. 10.

9. Nesse sentido: STF, MS n. 21.427-MG, DJU de 20.11.92, p.21611; STJ, MS n. 110-DF, DJU de 23.10.89, p.16187; MS n. 613-DF, DJU de 25.03.91, p.3203.

10. Ob. cit., p. 77 
mesmo bairro, participarem de certos empreendimentos, consumirem determinados produtos."

E prossegue a professora:" "Já nos chamados coletivos, existe um vinculo juridico, ou uma relação juridica-base, que une as pessoas pertencentes ao grupo: como os filiados a um sindicato, os membros de uma entidade associativa, as pessoas interessadas na preservação ambiental ou na eliminação da propaganda enganosa, que se associam para a defesa de seus interesses de categoria ou de classe."

Feitas as considerações que julgamos necessárias, passemos à análise dos direitos abrangidos pelo mandado de segurança coletivo.

a) partidos políticos

Primeiramente, no que se refere aos partidos políticos, verificamos ạue a alínea $a$, inciso LXX, art. $5^{\circ}$ da Constituição Federal adotou uma redação genérica, não impondo quaisquer limitações.

Assim, com relação a estes, questiona-se se o partido está legitimado apenas para defender os interesses de seus filiados ou se sua legitimação seria mais ampla.

Para Carlos Mário da Silva Velloso::" "no mandado de segurança coletivo, impetrado por partido político, o direito a ser pleiteado deve ser de natureza política, assim um direito político ou com este relacionado (CF, arts. 14 , 15 e 16) ou referido ao partido político (CF, art. 17). O partido político, outrossim, somente poderia impetrar mandado de segurança em favor de filiados seus."

A corroborar a tese do Ministro do STJ, podemos transcrever uma ementa do acórdão do STJ, referente aos Embargos Declaratórios em Mandado de Segurança de n. 197 , tendo como relator o Ministro Garcia Vieira: ${ }^{13}$

11. Ob. cit., p. 77.

12. "Do Mandado de Segurança e Institutos Afins na Constituição de 1988" In Mandados de Segurança e de Injunção, São Paulo, Saraiva, 1990, p. 97.

13. Nesse sentido: STJ, MS n. 1252, DЛ de 13.04.92, p. 4968. 
"EMBARGOS DECLARATÓRIOS MANDADO DE SEGURANÇA

COLETIVO - PARTIDO POLITICO.

A exemplo dos sindicatos e das associações, também, os partidos políticos só podem impetrar mandado de segurança coletivo em assuntos integrantes de seus fins sociais em nome de filiados seus, quando devidamente autorizados pela lei ou por seus estatutos. Não pode ele vir à Juizo defender direitos subjetivos de cidadãos a ele não filiados ou interesses difusos e sim direito de natureza política, como por exemplo, os previstos nos artigos 14 a 16 da Constituição Federal." (STJ - DJU, de 15-10-90, p.11182)

Por outro lado, Lúcia Valle Figueiredo, ${ }^{14}$ com apoio no art. $2^{\circ}$ da Lei n. 5.682/71, modificada pela Lei n. 6.767/79 (Lei Orgânica dos Partidos Políticos), entende que "tudo que atina aos direitos humanos fundamentais, à autenticidade do sistema representativo, pode ser objeto de mandado de segurança coletivo."

Oliveira. $^{15}$

Essa posição também é defendida por Lourival Gonçalves de

Conforme já salientamos, o texto constitucional não exige que o mandado de segurança coletivo seja impetrado por partidos políticos na defesa de seus membros. Desta forma, entendemos que os partidos políticos estão legitimados para a defesa dos interesses difusos. ${ }^{16}$ Esses interesses, aliás, são perfeitamente compativeis com o papel dos partidos políticos.

A nosso ver, os partidos políticos podem impetrar mandado de segurança coletivo para a defesa de:

a) direitos coletivos (institucionais),

b) direitos de alguns de seus filiados, desde que se possa dar tratamento coletivo e

c) interesses difusos.

14. Ob.cit., p. 22.

15. "Interesse processual e mandado de segurança coletivo". In Revista de Processo, São Paulo, v. 14 , n. 56, p. 80.

16. Nesse sentido: TRF 4 Região (RS) - AMS n. 402703, DJU de 29.01.92, p. 916. 
b) sindicatos, associações e entidades de classe

Já no que diz respeito à alínea $b$, do inciso LXX, do art. $5^{\circ}$ da $\mathrm{CF}$, entendemos que nesse caso o alcance dos direitos tutelados pelo mandado de segurança coletivo seria um pouco mais restrito.

Com efeito, o texto constitucional prevê a impetração do mandado de segurança coletivo por sindicato, entidade de classe e associação na "defesa dos interesses de seus membros ou associados." Em virtude disso, entendemos que no caso da alínea $b$, do inciso LXX, do art. $5^{\circ}$ da Constituição estão excluídos os interesses difusos.

Lourival Gonçalves de Oliveira, ${ }^{17}$ vislumbra nesse caso, a presença do "vinculo associativo capaz de transformar individuos em membros ou associados, o pressuposto da 'affectio societatis' $e$ o caracterizador da transcendência aos interesses de cada um deles."

Diniz Grangeia ${ }^{18}$ entende que "a expressão 'coletivo' usada para diferenciar este instituto do mandado de segurança individual, está associada à generalidade de interesse referente a uma categoria. Isso significa dizer que a lesão deve atingir todos os associados, sindicalizados ou partidários, indistintamente." (g.n.).

Essa posição, embora tenha algum respaldo jurisprudencial, parecenos ser excessivamente restritiva. A nosso ver não é necessário que o direito tutelado envolva a totalidade dos integrantes. Nada obsta a tutela de direitos individuais de parte da categoria, desde que seja possivel dar um tratamento coletivo. $^{19}$

Entendimento semelhante ao nosso apresentou o Ministro Sepúlveda Pertence, em seu voto proferido no Mandado de Segurança (Coletivo) n. 20.936-4 DF, às fls. 286: "Estou, ao contrário, em que no caso do sindicato ou da entidade de classe, será necessário e suficiente ao cabimento do mandado de segurança coletivo que o direito pleiteado em favor de filiados seus não seja alheio à sua condição de integrantes da respectiva categoria social ou econômica, ou da respectiva classe - independentemente do número ou da proporção daqueles que,

17. Ob. cit., p. 79.

18. "Pontos Controvertidos do Mandado de Segurança Coletivo e do Mandado de Injunção" In Revista dos Tribunais, São Paulo, v. 53, n. 10, p. 85

19. Nesse sentido: TJSP, RT 661/66. 
por se enquadrarem na situação-tipo deduzida em juízo, sejam os eventuais beneficiários da demanda."

\section{Legitimação:}

legitimação ativa

No mandado de segurança individual a questão da legitimação ativa não provoca maiores complicações. A regra geral é a ocorrência de legitimação ordinária, em que o próprio titular do direito líquido e certo impetra o writ.

Já no mandado de segurança coletivo o problema da legitimação tem causado bastante polêmica.

Da leitura do inciso LXX, art. $5^{\circ}$ da Constituição, claro fica que têm legitimidade para impetrar o mandado de segurança coletivo:

a) o partido político com representação no Congresso Nacional;

b) a organização sindical;

c) a entidade de classe;

d) a associação legalmente constituída.

$\mathrm{O}$ rol do inciso LXX, art. $5^{\circ}$, é taxativo. A impetração do mandado de segurança coletivo só pode ser realizada pelas entidades acima mencionadas. ${ }^{20}$

A legitimação dada pela Constituição aos partidos políticos na alínea $a$, do inciso LXX, do art. $5^{\circ}$, é bastante ampla. A única exigência constitucional para os partidos políticos é a necessidade de representação no Congresso Nacional.

No que se refere aos sindicatos, associações e entidades de classe ${ }^{21}$ também foram impostas poucas restrições: estarem legalmente constituídas e em funcionamento há pelo menos um ano.

20. O Supremo Tribunal Federal já decidiu no Mandado de Segurança n. 21059 -RJ, que o Estadomembro não tem legitimidade para impetrar mandado de segurança coletivo, sob o fundamento de que a enumeração contida no inciso LXX do art. $5^{\circ}$ da CF ser taxativa, sendo vedada a construção analógica. DJU de 19.10 .90 , p. 11486.

21. O STF se pronunciou em uma ação direta de inconstitucionaiidade: "não se caracteriza como entidade de classe a simples associação de empregados de determinada empresa, por não congregar uma categoria de pessoas intrinsecamente distinta das demais, mas somente agrupadas pelo interesse contingente de estarem a serviço de determinado empregador." (ADIN n. 34-DF, DJU de 28.04.1989, p. 6293). 
No mandado de segurança coletivo ocorre, a nosso ver, o fenômeno da substituição processual, pois as entidades legitimadas exercem em nome próprio direito alheio. ${ }^{22}$ Essa é a posição majoritária da doutrina.

A tese, todavia, não é pacifica. Ada Pellegrini Grinover ${ }^{23}$ defende " $a$ moderna tendência doutrinária que vê, na legitimação de entidades que ajam na defesa de interesses institucionais, uma verdadeira legitimação ordinária."

Como bem observou Araújo Cintra, ${ }^{24}$ "a substituição processual constitui caso de legitimação extraordinária autônoma (pois confere ao substituto a possibilidade de atuar em juizo com total independência, relativamente à pessoa que teria legitimação ordinária, e em posição correspondente à desta, se ordinário apenas fosse o critério adotado pela lei para definir a situação legitimante) $e$ concorrente (dado que a lei admite que no processo fique apenas o legitimado extraordinário, apenas o ordinário, ou ambos)."

Outro ponto controvertido no mandado de segurança coletivo é a necessidade ou não de autorização prévia por parte dos membros e associados das entidades através de assembléia geral. Aqui a jurisprudência também se divide. ${ }^{25}$

Celso Ribeiro Bastos ${ }^{26}$ teceu as seguintes considerações acerca da autorização prévia: "Para nós, num autêntico mandado coletivo, há uma verdadeira substituição processual; alguém age em nome próprio em defesa de interesse de outrem. A pessoa jurídica se sub-roga no direito dos seus próprios membros. Se, contudo, depararmo-nos com uma autorização, para atuação num determinado caso, este ato, a nosso ver, caracteriza um mandato."

Somos da opinião de que não se pode exigir das entidades a autorização prévia para impetração de mandado de segurança coletivo. A legitimação extraordinária dessas entidades foi dada pela própria Constituição, não

22. Nesse sentido: STF, RMS n. 21514, DJU de 18.06.93, p.12111. TRF $4^{2}$ Região (RS), AMS n. 402407, DJU de 08.04.92, p.8509; TST, RR n. 23373, DJU 14.02.92, p. 1249.

23. Ob. cit. p. 77.

24. "Estudos sobre a Substituição Processual no Direito Brasileiro" In Revista dos Tribunais, São Paulo, n. 438, p. 26.

25. Pela necessidade de autorização prévia: STJ, MS n. 915-DF, DJU de 18.05.92, p.6957; MS n. 1043-DF, DJU de 09.03.92, p.2528. TJSP, Ap. n. 121.324-1, Boletim AASP 1671/04; pela desnecessidade da autorização prévia: TSE, MSC n. 6, DJU de 06.10.89, p. 15542; TJSP, RT 657/74; TJMT, RT 660/157

26. Bastos, Celso Ribeiro \& Martins, Ives Gandra Comentários à Constituição do Brasil, São Paulo, Saraiva, 1989, p. 353. 
sendo possível quaisquer limitações à utilização do writ. Além disso, trata-se de hipótese de substituição processual autônoma.

Sendo inadmissível a autorização prévia, fica então a indagação: como impedir a violação da garantia do devido processo legal para os substituídos?

Tucci, $^{27}$ lembrando a experiência norte-americana com a Class Action, propõe que sejam assegurados aos membros e associados das entidades o direito de auto-exclusão (right to opt out) e a cientificação da impetração.

Essa solução nos parece ser a mais conveniente, pois de um lado coibem-se os eventuais abusos por parte das entidades substitutas; de outro, não se incompatibiliza com o mandado de segurança coletivo.

\section{Coisa Julgada:}

Por fim, resta a indagação: qual os limites dos efeitos da sentença no mandado de segurança coletivo?

O mais adequado nos parece a adoção da coisa julgada secundum eventum litis, semelhante ao que ocorre com as ações coletivas previstas na Lei $\mathbf{n}$. 8.078/90 (Código do Consumidor): a sentença fará coisa julgada erga omnes ou ultra partes.

\section{CONCLUSÃO}

1. Antes mesmo da atual Constituição já se cogitava da utilização do mandado de segurança para a defesa de interesses coletivos.

2. O mandado de segurança coletivo não é um instituto autônomo. Ele é espécie do gênero mandado de segurança, necessitando dos mesmos pressupostos deste.

3. A importância da previsão do mandado de segurança coletivo na atual Constituição está na consolidação desse instrumento coletivo.

4. A principal nota característica do mandado de segurança coletivo está na sua legitimação ativa, que acaba gerando reflexos no seu objeto e na coisa julgada.

27. Tucci, José Rogério Cruz e - 'Class Action' e Mandado de Segurança Coletivo, São Paulo, Saraiva, 1990, p. 50 . 
5. O mandado de segurança coletivo se presta para a defesa de interesse coletivo, interesse de alguns de seus membros se verificadas as condições para um tratamento coletivo e, no caso dos partidos políticos, estende-se aos interesses difusos.

6. Ocorre no mandado de segurança coletivo a figura da substituição processual autônoma e concorrente, não sendo admissível a exigência de autorização prévia.

7. Para se garantir o devido processo legal para os substituídos, deveriam ser assegurados o direito de auto-exclusão (right to opt out) e a cientificação da impetração.

8. Dever-se-ia adotar a adoção da coisa julgada secundum eventum litis no mandado de segurança coletivo.

9. Por fim, é inegável a conotação política existente no mandado de segurança coletivo, inclusive pela extensão dos impactos das decisões.

\section{BIBLIOGRAFIA}

BARBI, Celso Agrícola - "Mandado de Segurança na Constituição de 1988" in Revista de Processo, São Paulo, 15(57):7-12, jan./mar. 1990.

BASTOS, Celso Ribeiro \& MARTINS, Ives Gandra - Comentários à Constituição do Brasil. São Paulo, Saraiva, 1989.

BUZAD, Alfredo - Considerações sobre o Mandado de Segurança Coletivo. São Paulo, Saraiva, 1.992.

CARNEIRO, Athos Gusmão "Anotações sobre o Mandado de Segurança Coletivo" in Revista Jurídica, Porto Alegre, 40(180):5-22, out. 1992.

CHIOVENDA, Giuseppe - Instituições de Direito Processual Civil; tradução de J.Guimarães Menegale. São Paulo, Saraiva, 1965. v. 2.

CICOTE, Odival "Mandado de Segurança Coletivo". in Justitia, São Paulo, 52(150):96-104, abr./jun. 1990.

CINTRA, Antônio Carlos de Araújo "Estudos sobre a Substituição Processual no Direito Brasileiro". in Revista dos Tribunais, São Paulo, (438):24 
CRETElLA JÚNIOR, José - Os "Writs" na Constituição de 1988. Rio de Janeiro, Forense Universitária, 1989.

FARIA, Luiz Alberto Gurgel de - "Mandado de Segurança Coletivo: Legitimação e Interesse" in Revista dos Tribunais, São Paulo, 82(687):34-39, jan. 1993.

FERREIRA FILHO, Manoel Gonçalves - Curso de Direito Constitucional. $18^{\mathrm{a}}$ ed. São Paulo, Saraiva, 1990.

FIGUEIREDO, Lúcia Valle - Perfil do Mandado de Segurança. São Paulo, Revista dos Tribunais, 1989.

------ "Os Partidos Políticos e o Mandado de Segurança Coletivo" in Revista da Procuradoria Geral do Estado de São Paulo, São Paulo, (34):99-106, dez. 1990.

FIGUEIREDO, Marcelo - "As Novas Garantias Constitucionais e sua Procedimentalização: Questões Polêmicas" in Revista do Advogado. publicação da AASP, São Paulo, (34): 23-36, jun.1991.

FRANCO NETO, Ary Azevedo "Mandado de Segurança Coletivo" in Revista dos Tribunais, São Paulo, 81(677):7-12, mar. 1992.

GRANGEIA, Marcos Alaor Diniz - "Pontos Controvertidos do Mandado de Segurança Coletivo e do Mandado de Injunção" in Revista dos Tribunais, São Paulo, 53(10):1171-1177, out.1989.

GRECO FILHO, Vicente - Tutela Constitucional das Liberdades. São Paulo, Saraiva, 1989.

GRINOVER, Ada Pellegrini "Mandado de Segurança Coletivo: Legitimação, Objeto e Coisa Julgada" in Revista de Processo, São Paulo, 15(58):75-84, abr./jun. 1990.

MEIRELLES, Hely Lopes - Mandado de Segurança, Ação Popular, Ação Pública, Mandado de Injunção, Habeas Data. $13^{\mathrm{a}}$ ed. São Paulo, Revista dos Tribunais, 1989.

NERY JÚNIOR, Nelson - "Mandado de Segurança Coletivo" in Revista de Processo, 15(57):150-158, jan. 1990.

OLIVEIRA, Lourival Gonçalves de "Interesse Processual e Mandado de Segurança Coletivo" in Revista de Processo, São Paulo, 14(56):75-85, out./dez. 1989.

PACHECO, José da Silva O Mandado de Segurança e Outras Ações Constitucionais Típicas. $2^{\mathrm{a}}$ ed. São Paulo, Revista dos Tribunais, 1991. 
PASSOS, J. J. Calmon de - Mandado de Segurança Coletivo, Mandado de Injunção, Habeas Data: Constituição e Processo. Rio de Janeiro, Forense, 1991.

SANTOS, Ernane Fidelis dos "Mandado de Segurança Individual e Coletivo: Legitimação e Interesse" in Mandado de Segurança e de Injunção. São Paulo, Saraiva, 1990. p.125-134.

SIDOU, José Maria Othon Habeas Corpus, Mandado de Segurança, Mandado de Injunção, Habeas Data, Ação Popular: As Garantias Ativas dos Direitos Coletivos. Rio de Janeiro, Forense, 1992.

SณVA, José Afonso - Curso de Direito Constitucional Positivo. $6^{\text {a }}$ ed. São Paulo, Revista dos Tribunais, 1990.

TELXEIRA, Sálvio de Figueiredo "Mandado de Segurança: Uma Visão de Conjunto" in Mandados de Segurança e de Injunção. Saraiva, 1990. p.107124.

TEMER, Michel - Elementos de Direito Constitucional. $7^{\mathrm{a}}$ ed. São Paulo, Revista dos Tribunais, 1990.

TUCCI, José Rogério Cruz e Class Action e Mandado de Segurança Coletivo. São Paulo, Saraiva, 1990.

VEADO, Walter - "Mandado de Segurança Coletivo e Liminar" in Mandados de Segurança e de Injunção. São Paulo, Saraiva 1990. p.255-265.

VELLOSO, Carlos Mário da Silva - "Do Mandado de Segurança e Institutos Afins na Constituição de 1988" in Mandados de Segurança e Injunção. São Paulo, Saraiva, 1990. p.75-106.

WATANABE, Kazuo "Tutela Jurisdicional dos Interesses Difusos: a Legitimação para Agir" in A Tutela dos Interesses Difusos. São Paulo, Max Limonad, 1984. p.85-97 